\title{
Sobre a pertinência da noção de transição escola-trabalho no Brasil ${ }^{*}$
}

\author{
Alvaro A. COMin \\ ROGÉRIO JERÔNIMO BARBOSA
}

\begin{abstract}
RESUMO
A acelerada expansão do ensino superior no Brasil trouxe para o sistema de ensino indivíduos pertencentes a grupos de menor renda que frequentam cursos noturnos e arcam privadamente com os custos dos estudos. Uma boa parte deles tem idade mais avançada do que usualmente se imagina: não são, a rigor, estudantes que trabalham, mas trabalhadores que estudam. Neste artigo a suposição usual de que a educação superior deva conduzir os indivíduos a nichos ocupacionais de maior qualificação formal é invertida, em favor da ideia de que são as condições do mercado de trabalho e a inserção ocupacional já conquistada pelos indivíduos o que dá sustentação ao esforço de voltar a estudar em busca do diploma superior.
\end{abstract}

PALAVRAS-CHAVE: educação superior; mercado de trabalho; transição escola-trabalho; desenvolvimento econômico.

\section{ABSTRACT}

The fast expansion of universities in Brazil has opened up the superior educational system to students of low income groups, that attend evening courses and pay privately for tuition. Many are older than the average student: more than college students who happen to work, they are workers who go to college. This article disputes the received notion that a college degree enables people to occupy high skilled jobs, and suggests that it is the conditions of the labor market and occupational positions already obtained by these individuals that enables them to return to the educational system and grant themselves a college degree.

KEYWORDS: college; labor market; school-work transition; economic development.

[*] Este artigo é fruto do Projeto "Assessing the impact of higher education expansion on economic restructuring, occupational change and access to opportunities in Brazil and India. Collaborative Analysis of Microdata Resources", financiado pelo ESRC-UK, sob a coordenação geral da dra. Kate Purcell, do Institute for Employment Research (IER) da Universidade de Warwick-UK. Pelo lado brasileiro o trabalho foi realizado no Centro de Estudos da Metrópole (CEM-Cebrap) e coordenado por Nadya A. Guimarães. Álvaro Comin agradece ao apoio da Capes
Não há muita controvérsia quanto ao fato de que o desenvolvimento econômico depende da produção e disseminação de conhecimento - bem como das capacidades técnicas a ele associadas -, mesmo que a natureza desse conhecimento possa variar consideravelmente entre países e regiões. A educação, sobretudo a de nível superior, tornou-se, nas últimas décadas, um ativo altamente distintivo, capaz de promover (ou, na sua ausência ou baixa adequação, frear) o desenvolvimento. Para os indivíduos, o diploma de nível superior representa oportunidades de mobilidade social, por meio de carreiras profissionais mais promissoras quanto a realização pessoal, status social, direitos sociais e retornos salariais. 
O encontro entre qualificações e ocupações, contudo, não é automático. Demanda tempo e depende da qualidade do desenvolvimento econômico. Por mais que as dinâmicas do mercado de trabalho e do sistema educacional estejam entrelaçadas de muitas maneiras, o curso de cada uma delas obedece a diferentes lógicas e temporalidades. As demandas presentes do mercado de trabalho refletem o estado atual do sistema produtivo, que, por sua vez, é o resultado dos investimentos já realizados no passado. Os investimentos em educação projetam seus resultados em longo prazo, o que significa que não podem ser vistos meramente como resposta às demandas correntes. As grandes desvantagens educacionais que hoje constrangem o desenvolvimento do Brasil são o produto da insuficiência de investimentos no correr de muitas décadas pregressas.

Afora todos os problemas ainda enfrentados nos níveis de educação básica e intermediária (de qualidade em ambos os casos e de cobertura no segundo), a educação superior é um elemento crítico no que se refere a delinear mudanças econômicas no futuro; e, assim, definir se as oportunidades de mobilidade social serão maiores ou menores, quais grupos sociais terão maiores chances de aproveitar essas oportunidades e quais deverão ser apoiados por políticas específicas. Assim, os efeitos das mudanças recentes no arcabouço institucional e nos níveis de investimento sobre a qualificação da força de trabalho, a distribuição da renda ou as chances de mobilidade social também devem ser avaliados com cautela.

Desde meados da década de 1990, assistimos a um conjunto de reformas institucionais que induziram à forte expansão do ensino superior. A estratégia básica no momento inicial foi a de estimular a oferta por meio de instituições privadas, seguida de uma flexibilização na oferta de cursos, criando alternativas ao bacharelado convencional de quatro anos, através de cursos sequenciais, tecnológicos e à distância. Grosso modo, até então, as universidades públicas atenderam às demandas educacionais das classes médias e altas; ao setor privado em expansão coube crescentemente a missão de absorver estudantes provenientes de estratos de renda inferiores, adequando-se a seus reduzidos orçamentos. O crescimento do setor privado fortaleceu, assim, a provisão de educação superior, predominantemente, através de cursos de baixo custo, em geral voltados às humanidades, ao direito e à administração. A oferta de cursos das chamadas "ciências duras", como engenharia, medicina, física, biotecnologia e química, permaneceu, majoritariamente, sob iniciativa das universidades públicas.

A partir de 2004, ganham força iniciativas governamentais voltadas tanto para subsidiar o ingresso de indivíduos de baixa renda no setor privado de ensino (caso do Prouni) quanto para a expansão de vagas no setor público; assim como políticas específicas de pela oportunidade de permanecer sete meses, ao longo de 2010 , no IER-Warwick, com o auxílio de uma bolsa de pós-doutorado. Os autores agradecem também a Flávio Carvalhaes, Bruna Gisi e Alexandre Abdal pela leitura e sugestões.

[1] Ver Carvalho, Cristina H. A. de. A política pública para a educação superior no Brasil (1995-2008). Ruptura e/ou continuidade? Campinas: tese de doutoramento, IE-Unicamp, 2011. 
inclusão no ensino superior, como o Reuni e os programas de ação afirmativa. Dado que a maior parte das vagas de ensino superior se encontra em instituições privadas e que os programas de subsídios públicos recobrem apenas uma fração destas, é bastante razoável assumir que o forte aquecimento do mercado de trabalho, com aumento mais que proporcional dos estratos salariais mais baixos, colaborou de forma significativa para a rápida expansão do ensino superior na última década.

A grande questão é saber até que ponto o crescimento do número de indivíduos com diplomas de nível superior vem se traduzindo (ou poderá vir a se traduzir) em melhores oportunidades de trabalho, necessariamente associadas a ocupações e setores econômicos mais produtivos. Mesmo que se pudesse abstrair a enorme heterogeneidade qualitativa da educação recebida pelos milhões de novos diplomados no Brasil (o que, na prática, os dados utilizados neste artigo nos forçam a fazer), o desejado encontro entre qualificações e ocupações não depende apenas da política educacional; diz respeito, em última instância, ao modelo de desenvolvimento econômico.

\section{OS “NOVOS GRADUADOS”: TRABALHADORES E ADULTOS}

O quadro educacional brasileiro se alterou substantivamente nas últimas três décadas: segundo dados da PNAD, em 1982, a escolaridade média do brasileiro era de 3,5 anos de estudo; em 2009, esse valor chegou a 6,1. Em 27 anos, a educação formal da população brasileira quase dobrou. Considerando os níveis educacionais completos, em 1995 , quando a média de anos de estudo da população como um todo já era de 5,2 anos, 78,4\% não possuíam nenhum nível de ensino completo, $9,6 \%$ tinham o ensino fundamental completo, $8,8 \%$ o ensino médio completo e 3,3\% o ensino superior completo. Embora a variação da média de anos de estudo entre 1995 e 2009 tenha sido de pouco menos de um ano, a distribuição dos indivíduos, quanto aos graus completos, se alterou enormemente: $59 \%$ não possuíam nenhum nível de ensino completo, $13,5 \%$ possuíam ensino fundamental, $21 \%$ ensino médio e 6,5\% ensino superior. A quantidade de pessoas sem níveis de ensino completos se reduziu em números absolutos e relativos, enquanto, paralelamente, os níveis de ensino mais elevados foram os que apresentaram crescimento mais acelerado, bem acima da média, dobrando sua participação relativa.

De todos os níveis de ensino, o superior é o único que vem apresentando aceleração em suas taxas de expansão, esboçando uma tendência exponencial. Há dois pontos de maior acentuação: no final dos anos 1990, seguindo as mudanças no marco regulatório que induziram à expansão no setor privado de ensino; e, a partir de 2005 , sob o 
efeito das iniciativas governamentais já mencionadas. Nas três décadas consideradas, o percentual de graduados no mercado de trabalho praticamente triplicou; em números absolutos o aumento foi de cerca de cinco vezes, passando de 1,9 milhão, em 1982, para mais de 10,3 milhões, em 2009.

\section{GRÁFICOI}

Evolução do percentual de graduados na população ocupada²

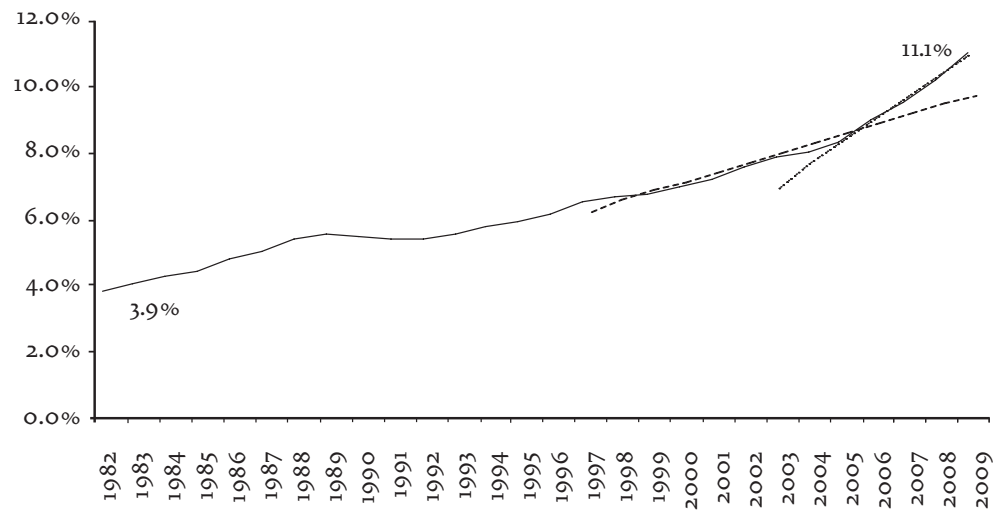

Segundo dados do INEP, em $2008,75 \%$ das novas matrículas em nível superior ocorreram em instituições privadas. Nesse mesmo ano, quase dois terços dos graduados frequentavam cursos noturnos $(62,6 \%)$ - e desses a maioria trabalhava em tempo integral. Os dados da PNAD, relativos ao conjunto de indivíduos frequentando educação de nível superior, mostram, claramente, que o crescimento das vagas atingiu com mais força a população ocupada, mais especificamente a população que trabalha mais de 40 horas por semana.

TABELA I

Horas despendidas semanalmente no trabalho principal entre os estudantes de graduação (1995-2009)

\begin{tabular}{|c|c|c|c|}
\hline & 1995 & 2001 & 2009 \\
\hline Não trabalham & $35,9 \%$ & $35,0 \%$ & $31,4 \%$ \\
\hline Até 19 horas & $4,3 \%$ & 3,65 & $3,4 \%$ \\
\hline $20-29$ horas & $10,7 \%$ & $11,3 \%$ & $9,5 \%$ \\
\hline $30-39$ horas & $11,5 \%$ & $10,1 \%$ & $11,2 \%$ \\
\hline 40 horas ou mais & $37,6 \%$ & $40,1 \%$ & $44,6 \%$ \\
\hline Total & $100 \%$ & $100 \%$ & $100 \%$ \\
\hline
\end{tabular}

[2] Os valores deste gráfico diferem um pouco daqueles apresentados anteriormente porque considerou-se aqui apenas as pessoas que, além de estarem ocupadas, especificaram em que tipo de ocupação trabalhavam. 
[3] Ver Shavit, Muller e Clare. From school to work: a comparative study of educational qualifications and occupational destinations. Oxford: Claredon Press, 1997.

[4] Idem, ibidem.

[5] As informações produzidas pelos pesquisadores indianos associados ao projeto mencionado na nota 1 acima sugerem que também em relação à Índia o Brasil seja um caso excepcional, já que o perfil etário dos universitários indianos não difere muito do dos ingleses. Para o caso da Índia, ver Unni, J. “Employment Growth, Knowledge Intensity and Higher Education in India", Paper apresentado na First Asian Population Association Conference, grupo temático Labour Force, Employment and Education, Nova Deli, 16-20/11/2010; e Basant, R. e Sen, G. "Who participates in Higher education in India? Rethinking the role of affirmative action". Paper apresentado no Observer Research Foundation, set. 2008.

[6] Recorremos à ISCO-88 como forma de tornar compativeis os diferentes sistemas de classificação ocupacionais brasileiros usados na PNAD durante as últimas três décadas. $\mathrm{O}$ nível mais agregado de classificação foi usado para atenuar os inevitáveis ruídos provocados pelas compatibilizações entre os códigos dos diferentes sistemas de classificação e porque, sendo a PNAD uma pesquisa amostral, em níveis de maior desagregação faltaria representatividade estatística para muitas ocupações, problema que seria pesadamente agravado quando se segregassem apenas os indivíduos com escolaridade superior.
O perfil etário desses estudantes de nível superior sugere que são, em sua maioria, indivíduos já há muito inseridos no mercado de trabalho, que retornam aos estudos em proporção cada vez maior, não raro após uma trajetória de interrupções nos estudos ou atraso escolar. É certo que o Brasil atravessa um ciclo de envelhecimento populacional, que de maneira geral deve se refletir nos variados segmentos sociais. Contudo, as noções convencionais de transições educacionais e de transição escola-trabalho estão associadas a faixas etárias específicas e a uma linearidade nos percursos individuais 3 ; sendo esperável que as coortes mais jovens apresentem percentuais mais elevados de graduados do que as mais velhas. Assim, o estudante "regular", egresso do ensino médio aos 17 ou 18 anos, e que prossegue nos estudos de nível superior, terminaria sua graduação porvolta dos 25 anos. Esseé de fato um padrão bastante difundido nos países mais ricos 4 e provavelmente entre as classes de renda mais elevada no Brasil. Em 1995, 31\% dos estudantes de graduação brasileiros possuíam mais de 25 anos. Em 2009 , esse valor subiu para 40\%. Mesmo que a maioria absoluta dos estudantes esteja na faixa etária "esperada", a tendência, nitidamente, é de envelhecimento dessa população. Isso faz do Brasil um caso bastante discrepante em relação à maioria dos países em que o ensino superior é mais amplamente difundido5.

Considerando esse padrão "invertido" de transição, que leva do trabalho à escola, e que a extensão desse padrão é um processo recente eem aceleração,é duvidoso que a mera análise da alocação ocupacional presente dos indivíduos com recém-adquirida escolaridade superior (vale dizer, do exame do equilíbrio entre oferta e procura dessa mão de obra) permita avaliar, adequadamente, os impactos dos ganhos de escolaridade referentes a sua inserção profissional. Por ora, parece mais razoável trabalhar com a hipótese de que são a inserção profissional já alcançada pelos indivíduos e a busca por se manter e progredir no mercado de trabalho o que explica esse movimento de volta à escola. Na próxima seção, o exame das mudanças na estrutura ocupacional brasileira tem por objetivo, portanto, jogar luz sobre a "origem" sócio-ocupacional dos novos graduados e não sobre seu "destino", sobre o qual talvez seja ainda muito cedo para falar.

\section{A ORIGEM PROFISSIONAL DOS “NOVOS GRADUADOS” E A EVOLUÇÃO DA ESTRUTURA OCUPACIONAL}

Para efeitos empíricos, as mudanças na estrutura ocupacional são examinadas, nesta seção, por meio da distribuição dos graduados pelos Grandes Grupos Ocupacionais (GG), da classificação internacional de ocupações ISCO-886. A tabela abaixo apresenta a composição dos grupos ocupacionais, em 1982 e 2009 , para o conjunto da força 
TABELA 2

Frequência de ocupados e de graduados por grandes grupos ISCO (1982 e 2009)

\begin{tabular}{|c|c|c|c|c|c|c|c|c|}
\hline \multirow{2}{*}{ Grandes grupos } & \multicolumn{4}{|c|}{1982} & \multicolumn{4}{|c|}{2009} \\
\hline & TOTAL & $\%$ & GRADUADOS & $\%$ GRAD. & TOTAL & $\%$ & GRADUADOS & \% GRAD. \\
\hline Forças Armadas & 888.502 & $1,9 \%$ & 27.714 & $3,1 \%$ & 2.383 .779 & $2,6 \%$ & 66.590 & $2,8 \%$ \\
\hline Gerentes e altos func. adm. Pública & 3.307 .943 & $6,9 \%$ & 488.182 & $14,8 \%$ & 6.460 .922 & $7,0 \%$ & 1.792 .685 & $27,7 \%$ \\
\hline Profissionais & 2.146 .093 & $4,5 \%$ & 973.027 & $45,3 \%$ & 7.309 .465 & $7,9 \%$ & 4.933 .063 & $67,5 \%$ \\
\hline Técnicos & 1.745 .185 & $3,6 \%$ & 159.611 & $9,1 \%$ & 4.790 .857 & $5,2 \%$ & 1.205 .558 & $25,2 \%$ \\
\hline Trabalhadores de escritório & 3.287 .867 & $6,9 \%$ & 165.109 & $5,0 \%$ & 8.010 .792 & $8,6 \%$ & 1.167 .522 & $14,6 \%$ \\
\hline Trabalhadores do comércio e serviços & 1.273 .141 & $2,7 \%$ & 7.776 & $0,6 \%$ & 5.677 .812 & $6,1 \%$ & 154.520 & $2,7 \%$ \\
\hline Trabalhadores qualificados da agricultura & 4.041 .414 & $8,4 \%$ & 2.428 & $0,1 \%$ & 3.958 .045 & $4,3 \%$ & 51.952 & $1,3 \%$ \\
\hline Artesãos e trabalhadores da indústria leve & 7.827 .651 & $16,3 \%$ & 13.043 & $0,2 \%$ & 15.184 .510 & $16,4 \%$ & 246.429 & $1,6 \%$ \\
\hline Trabalhadores da indústria pesada & 3.691 .139 & $7,7 \%$ & 8.391 & $0,2 \%$ & 6.559 .987 & $7,1 \%$ & 183.863 & $2,8 \%$ \\
\hline Ocupações elementares & 19.716 .916 & $41,1 \%$ & 33.195 & $0,2 \%$ & 32.353 .084 & $34,9 \%$ & 510.307 & $1,6 \%$ \\
\hline Total & 47.925 .851 & $100,0 \%$ & 1.878 .476 & $3,9 \%$ & 92.689 .253 & $100,0 \%$ & $|10.312 .489|$ & $11,1 \%$ \\
\hline
\end{tabular}

de trabalho ocupada e para o subconjunto dos ocupados que possuem ensino superior. Tem-se, assim, para cada Grande Grupo Ocupacional suas dimensões e sua "densidade em graduados".

As ocupações que tradicionalmente empregam trabalhadores graduados (como medicina, engenharia, direito e arquitetura) estão reunidas no grupo dos Profissionais (GG2). Quase por definição, esse grupo apresenta a mais elevada densidade, isto é, o mais alto percentual de indivíduos com ensino superior, em ambos os extremos da série, observado o salto de pouco menos da metade para dois terços dos ocupados. A tabela não mostra, mas parte importante do crescimento observado nesse grupo se deve à notável transformação no perfil de grupos ocupacionais específicos. Dois bons exemplos, ambos muito numerosos e eminentemente femininos, são as professoras dos vários níveis de ensino e as enfermeiras, que tiveram seus requerimentos elevados do ensino médio para o superior, por força de regulamentações públicas.Apesar de ser uma tendência em si positiva, parece paradoxal que o crescimento dos cursos de pedagogia seja comumentelembrado como evidência da inadequação e do desperdício que caracterizariam a atual expansão do ensino superior no Brasil.

O grupo dos Gerentes e Altos Funcionários da Administração Pública e Privada (GG1) reúne, além dos gerentes propriamente ditos, diretores, presidentes de empresas e ocupantes de altos cargos políticos (inclusive eletivos). Trata-se de uma categoria de ocupados em posições de mando e autoridade que, dependendo das características 
setoriais e empresariais, requerem conhecimento especializado. Esse fato justifica sua segunda posição com relação à densidade de graduados, que passa de $15 \%$ para $28 \%$, em valores arredondados. Não chega a um terço, portanto, o número de profissionais em funções de gestão e comando com formação de nível superior, o que sugere que o elevado número de cursos e matrículas em administração de empresas e correlatos seja menos disfuncional do que se imagina.

O grupo dos Técnicos (GG3) é composto de trabalhadores que detêm um conhecimento especializado, mas que não requer, tradicionalmente, formação acadêmica. São habilidades adquiridas através do ensino vocacional (usualmente de ensino médio) ou até mesmo exclusivamente por meio da prática do trabalho. Em 1982, pouco menos de $10 \%$ dos técnicos possuíam diploma de ensino superior; em 2009 , esse número se elevou para $25 \%$, aproximando muito o perfil desse grupo ao dos Gerentes.

O grupo dos Trabalhadores de Escritório (GG4) congrega principalmente as chamadas ocupações não manuais de rotina; algumas delas implicando também a posse de conhecimentos técnicos e formações específicas, caso de contadores, estatísticos empresariais e analistas de finanças. Para essa categoria, a Organização Internacional do Trabalho assume que as habilidades exigidas no trabalho não implicam formação maior do que ensino médio ou técnico. No entanto, nessas três décadas, esse grupo multiplicou por três seu percentual de graduados, saltando de $5 \%$ para quase $15 \%$.

Os grupos ocupacionais de 5 a 9 (Trabalhadores do Comércio e Serviços - GG5, Trabalhadores Qualificados da Agricultura - GG6, Artesãos e Trabalhadores da Indústria Leve - GG7, Trabalhadores da Indústria Pesada - GG8, e Trabalhadores de Ocupações Elementares - GG9) representam (e representavam em 1982) a maior fatia da força de trabalho brasileira, abrigando quase $70 \%$ dos ocupados. A maior parte se encontra no grupo das Ocupações Elementares (formado por vendedores de rua, domésticas, porteiros, entregadores, vigias, trabalhadores não qualificados da agricultura, entre outros). São ocupações para as quais não se pressupõe níveis específicos de formação. Refletindo esse fato, verificamos, nos dois períodos, pequenos percentuais de graduados em cada um desses grupos.

O fato de queem todos os grupos houve crescimento do percentual de graduados significa que o crescimento do pessoal com ensino superior foi mais rápido do que o crescimento demográfico dos ocupados. No entanto, há uma imensa diferença de magnitude entre as ocupações mais e menos densas em graduados.

Os Gráficos 2A e 2B tomam o grupo dos Profissionais, o mais denso em graduados, como referência. O Gráfico $2 \mathrm{~A}$ apresenta o crescimento acumulado de todos os ocupados, bem como dos graduados, tendo 


\section{GRÁFICO 2A}

Crescimento percentual acumulado de todos os ocupados e dos graduados no grupo dos Profissionais (ano-base: 1982)

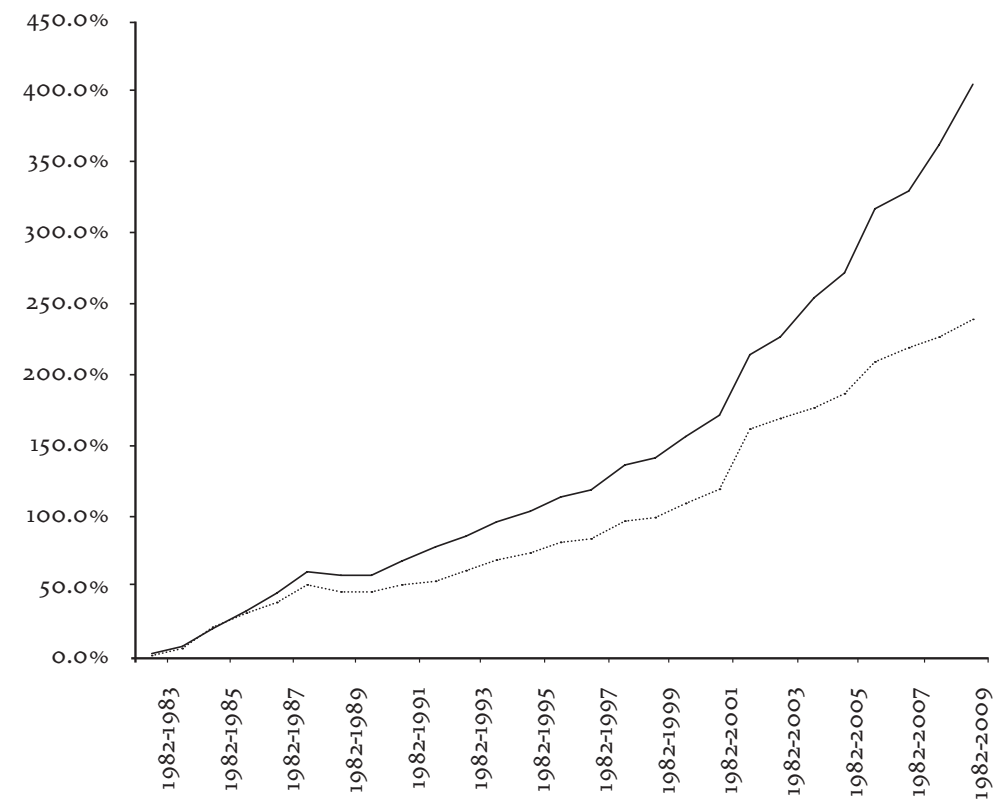

\section{GRÁFICO 2B}

Razão entre 0 crescimento acumulado dos graduados e de todos os ocupados no grupo dos Profissionais

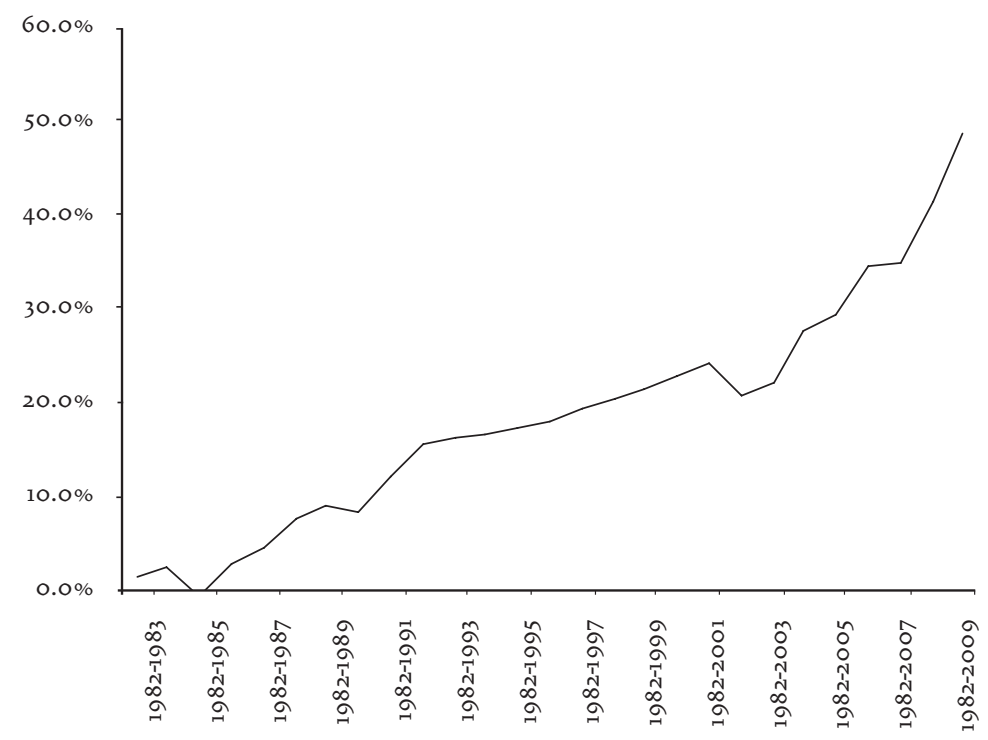


1982 como ano base. Ao final dessa série de 28 anos, a ocupação é cerca de $250 \%$ maior (isto é, 3,5 vezes o tamanho que possuía no início); simultaneamente, o número absoluto de graduados aumentou $400 \%$; ou seja, em 2009, temos cinco vezes o número de indivíduos com ensino superior do que havia em 1982.O Gráfico 2 B opera a divisão entre as duas séries e revela que, no acumulado, os graduados cresceram $50 \%$ mais rápido do que o grupo ocupacional como um todo. Por isso, como vimos na Tabela 2, a proporção de graduados passou de $45,3 \%$ para $67,5 \%$.

Os gráficos seguintes mostram que o grupo das Ocupações Elementares (o mais baixo do ponto de vista do status sócio-ocupacional e o mais numeroso no mercado de trabalho) passou por um processo quantitativamente muito distinto. Enquanto a ocupação como um todo cresceu cerca de $65 \%$, o número de graduados aumentou mais de 15 vezes. Isso significa dizer que, quando a frequência relativa de pessoas com ensino superior passa de 0,2\%, em 1982, para 1,6\%, há oito vezes mais chance de um indivíduo nessa ocupação ter concluído algum curso superior.

Obviamente, estamos tratando de fenômenos com proporções muito diversas. Enquanto, em 2009 , pouco mais de 7 milhões de indivíduos faziam parte do GG2 (e desses, quase 5 milhões eram graduados), o GG9 era composto de mais de 32 milhões de pessoas (cerca de 510 mil sendo graduadas). Logo, os graduados estão empregados, em sua maioria, em grupos ocupacionais que tradicionalmente formam seu principal nicho. Mas chama a atenção a velocidade (em aceleração) com que cresce o número de pessoas com ensino superior em ocupa-

\section{GRÁFICO 3A}

Crescimento percentual acumulado de todos os ocupados e dos graduados no grupo das Ocupações Elementares (ano-base: 1982)

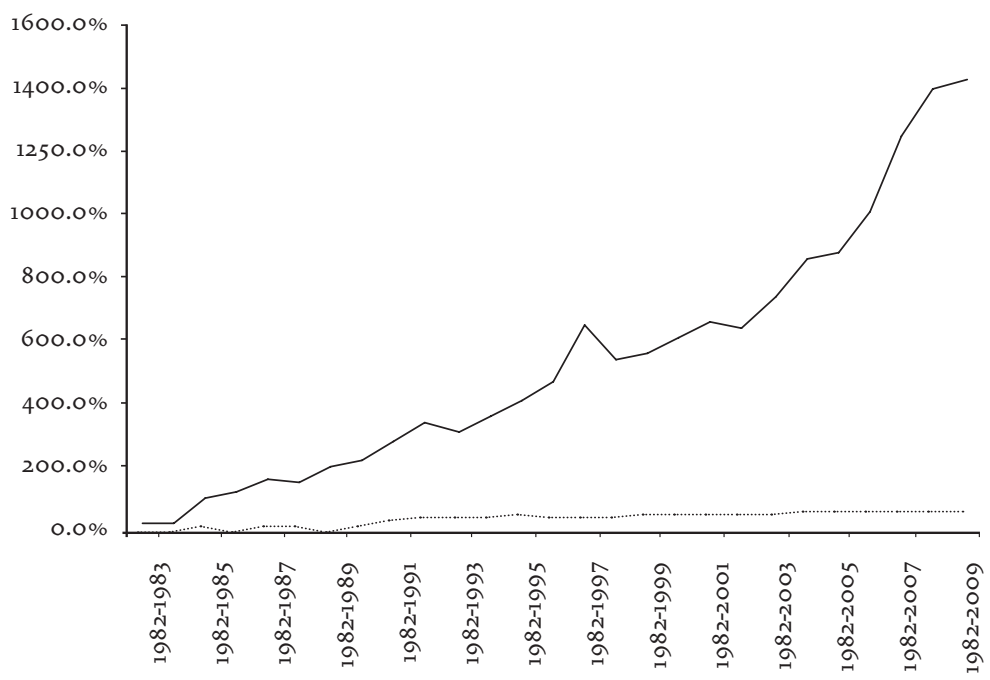


GRÁFICO 3B

Razão entre o crescimento acumulado dos graduados e de todos os ocupados no grupo das Ocupações Elementares

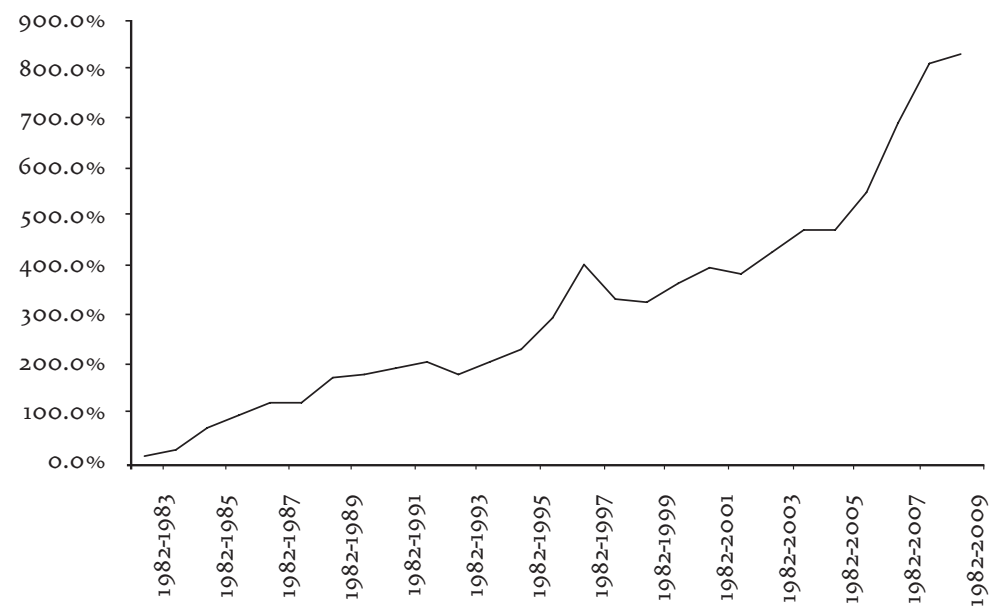

ções que formalmente não requerem mais do que o ensino médio ou apenas o fundamental. Em 1982, o número absoluto de graduados no grupo dos profissionais era 14,7 vezes maior do que entre as ocupações elementares; em 2009, essa diferença se reduziu para 9,7 vezes.

O gráfico abaixo fornece uma perspectiva sintética desse movimento de transformação da estrutura ocupacional. O eixo vertical traz os resultados da divisão entre o número absoluto de ocupados, em 2009 e 1982, enquanto o eixo horizontal expressa a razão entre a quantidade de graduados para os mesmos anos.

\section{GRÁFICO 4}

Comparação do crescimento dos graduados e de todos os ocupados em todos os grandes grupos ISC0-88 (1982-2009)

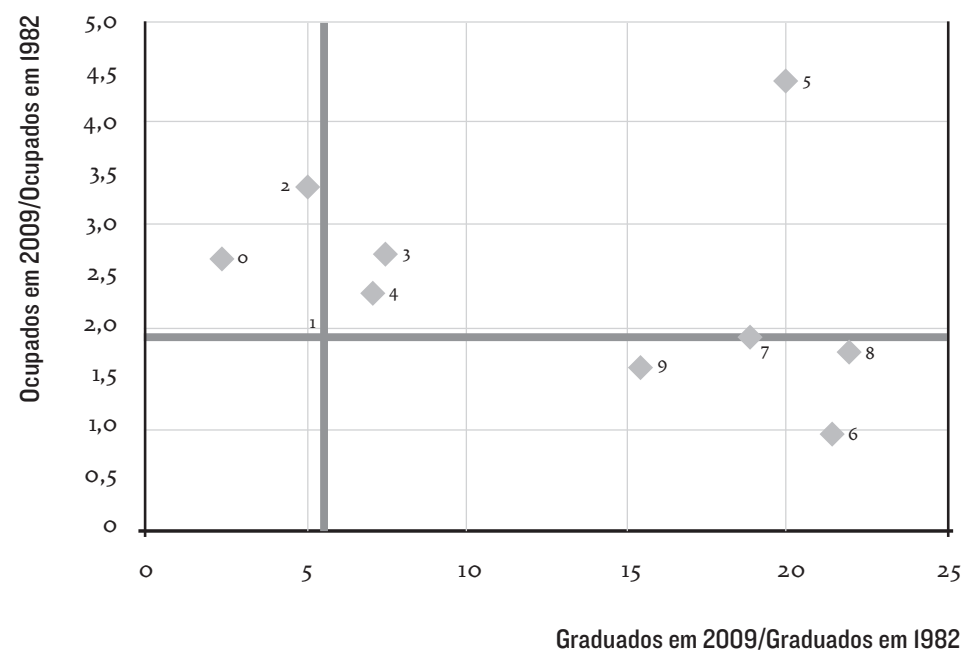


[7] Ver Comin, A. A. "Mudando sem sair do lugar: emprego e estrutura ocupacional em São Paulo". In: Guimarães, Nadya A., Cardoso, Adalberto, Elias, Peter e Purcell, Kate (orgs.). Mercados de trabalho e oportunidades. Reestruturação econômica, mudança ocupacional e desigualdade na Inglaterra e no Brasil. $1^{\text {a }}$ ed. Rio de Janeiro: FGV, 2008, pp.181-230.
Em todos os grandes grupos ocupacionais a taxa de crescimento dos graduados é superior à taxa de crescimento da própria ocupação. No entanto, há três padrões distintos de variação, representados por aglomerados de pontos no diagrama de dispersão.

Um aglomerado diz respeito às ocupações de códigos iniciados por números de o a 4 (forças armadas, gerentes, profissionais, técnicos e trabalhadores de escritório). Como todas elas apresentam um crescimento geral superior ao da média do mercado de trabalho no período, seu tamanho em 2009 é cerca de 2 a 3,5 vezes superior ao de 1982. A quantidade de indivíduos com ensino superior também aumentou bastante, entre 2,4 e 7,6 vezes - no entanto, para os grupos o, 1 e 2 esse crescimento é inferior ao da média de todas as ocupações (representada pela linha vertical). O segundo aglomerado de pontos marca um padrão bem contrastante: são ocupações com requisitos educacionais formalmente menores, que demograficamente cresceram a taxas iguais ou menores do que as do mercado de trabalho como um todo, mas cujo número absoluto de graduados aumentou entre 15 e 22 vezes. Por último, temos um ponto discrepante de todos os demais, que representa os trabalhadores do comércio e dos serviços. Esse grupo foi o que mais cresceu em termos absolutos no período $(4,5$ vezes $)$ e, simultaneamente, teve seu número de graduados aumentado cerca de 20 vezes.

De certa forma, o movimento observado no eixo vertical é esperado: reflete as mudanças mais gerais que a economia brasileira experimentou a partir de 1990, com o maciço encolhimento do emprego no setor industrial (GGs 7 e 8) e, em menor escala, também nos setores primários (GG6), e o crescimento dos serviços em geral (GGS I a 5)7. O que se observa no eixo horizontal, contudo, é bastante contraintuitivo. Em 1982, havia cerca de 230 mil graduados trabalhando em ocupações dos Grandes Grupos 5 a 9 (aqueles para os quais não se pressupõe demanda por educação formal de nível superior); em 2009 , esse número ultrapassou 2,3 milhões. Não há como checar, por meio da PNAD, até que ponto as qualificações desses ocupados com escolaridade superior correspondem ou não às ocupações que efetivamente exercem. A hipótese já anunciada deste artigo é a de que esse crescimento reflete, na verdade, a afluência dos indivíduos de classes de renda inferior ao ensino superior, como resultado primeiro das políticas de expansão da oferta, sobretudo nos anos 1990; e, depois, ao longo dos anos 2000 , pela forte expansão do emprego e da renda que atingiu mais que proporcionalmente esses estratos sociais, complementados por programas específicos de subsídio e inclusão. Vale repetir: o que os dados apresentados até aqui esclarecem, principalmente,é a "origem" social dos novos graduados e não seu "destino" ocupacional. Por último, cumpre examinar o que ocorreu com a renda do trabalho. 
As análises sobre a renda serão limitadas ao intervalo de tempo entre 1995 e 2009 . Os bem conhecidos efeitos da inflação crônica e intensa sobre a denominação dos valores monetários - entre eles o fato de o Brasil ter mudado seis vezes de moeda, entre 1984 e 1994 desaconselham a inclusão do período anterior neste passo.

O gráfico a seguir exibe os valores da mediana da renda do trabalho principal e do salário mínimo, com valores deflacionados pelo IPCA, até setembro de 2009 (mês de aplicação da PNAD). Entre 1995 e o início da década de 2000 , a mediana da renda esboça um pequeno movimento de declínio e o salário mínimo um leve crescimento (Gráfico 5), mas se comparamos esse intervalo de tempo com o subsequente, a partir de 2003 , de clara ascensão tanto dos salários quanto do salário mínimo, podemos dizer que o primeiro momento é de estabilidade. Como se sabe, a tendência do primeiro período acompanha menores índices de crescimento econômico e maiores taxas de desemprego; a do segundo, o cenário inverso, elevação das taxas de crescimento econômico e um forte ciclo de expansão do emprego. Ao longo de todo esse período, o número de ocupados com educação superior se expande aceleradamente, como se viu no Gráfico 1 .

O Gráfico 6 traz a decomposição da mediana da renda por nível de ensino. Os dados mostram que os graduados possuem renda mui-

GRÁFICO 5

Mediana da renda do trabalho principal e valores do salário mínimo entre 1995 e 2009 (em R\$ de 09/2009)

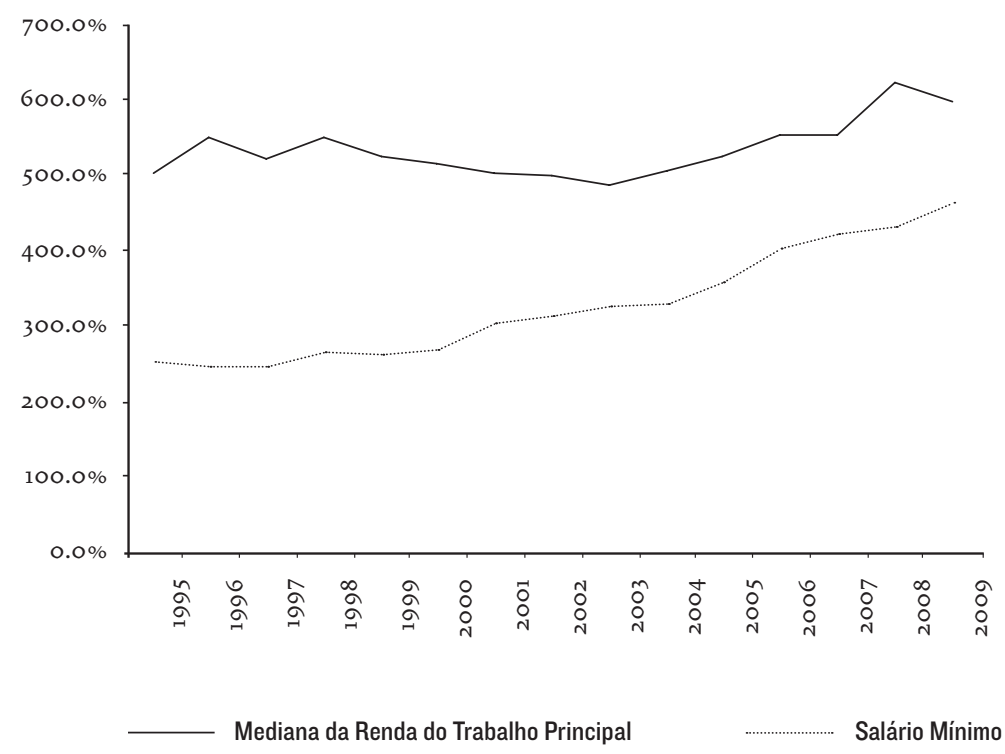


[8] Ver Soares, Sergei. “PNAD 2009 — Primeiras análises: distribuição de renda entre 1995 e 2009 ". Comunicados IPEA, 2010, n. 63 . to superior à dos demais grupos de escolaridade, mas que sofreram perdas muito mais acentuadas, que se estenderam até o ano de 2005 , quando esta se estabiliza, um pouco abaixo de 2 mil reais (em valores de 2009), ou seja, cerca de 630 reais a menos do que no ano inicial (queda acumulada de $25 \%$ no período). Ao contrário dos demais grupos, sua renda não guarda relação com o movimento ascendente do salário mínimo e da renda média, na última década. Os ocupados dos grupos de menor escolaridade também sofreram grandes perdas salariais, sendo 2004 o fundo do vale. Até esse ponto, os indivíduos portadores do diploma de ensino médio haviam acumulado perdas de $36 \%$, e os de nível fundamental, de $24 \%$. E mesmo com a recuperação posterior dos salários desses grupos, em 2009, os ocupados de nível médio e fundamental ainda recebiam rendas reais inferiores às de 1995.

Confirmando o que diversos estudos vêm mostrando ${ }^{8}$, foram os ocupados sem nenhum nível de ensino completo os que mais se beneficiaram. Seus rendimentos permaneceram relativamente estáveis até 2005 , flutuando em torno de 380 reais. Em 1995, esse valor equivalia a 1,5 salário mínimo. Com a valorização do salário mínimo, a distância entre esse e os rendimentos dos trabalhadores que não possuíam nem ensino fundamental foi se reduzindo gradativamente, até que, em 2005, os valores se igualaram. É nesse ponto que os salários desse grupo passam a acompanhar os aumentos reais do salário mínimo, de tal forma que, em 2009 , seus rendimentos foram $22 \%$ maiores do que no início da série.

Ainda assim, os rendimentos dos vários níveis de ensino são claramente hierarquizados. Para cada grau de escolaridade completo há um "prêmio salarial". Operacionalmente, o prêmio salarial pela graduação pode ser definido como a diferença percentual entre a renda

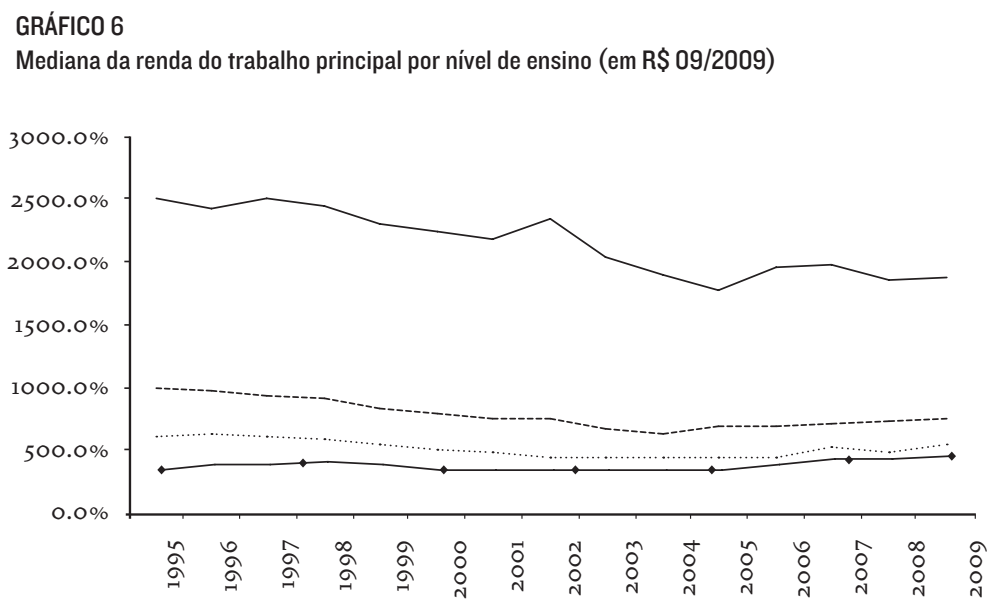

GRÁFICO 6

ensino superior completo ensino fundamental completo

ensino médio completo nenhum grau completo 
dos indivíduos com ensino superior e a dos que possuem apenas o ensino médio, dentro de um mesmo grupo ocupacional. Como forma de controlar a heterogeneidade interna dos Grandes Grupos Ocupacionais, bem como de isolar o efeito da graduação sobre a renda, foram construídos dois modelos de regressão múltipla, replicados para todos os anos, entre 1995 e 2009; em ambos, a variável dependenteé o logaritmo natural da renda do trabalho principal.

O primeiro (Modelo I) traz como variáveis de teste o nível de ensino (nenhum nível completo, ensino fundamental, ensino médio e graduação) e os Grandes Grupos Ocupacionais. Para especificar as condições em que o trabalho é realizado, adicionamos variáveis de controle sobre o setor econômico (atividades primárias, indústria tradicional, indústria moderna, construção, serviços distributivos, serviços produtivos, serviços sociais, serviços pessoais e administração pública); posição na ocupação (assalariado informal, assalariado formal, empregador, trabalhador doméstico e trabalhador por conta própria); idade, idade ao quadrado (ambas como proxy de experiência no trabalho e do "efeito carreira"); e número de horas trabalhadas por semana. Além disso, foram incluídos outros fatores que a literatura aponta, canonicamente, como importantes determinantes da renda: sexo, cor e macrorregiões do Brasil. Esse modelo visa estimar o efeito médio da graduação sobre a renda, permitindo o mapeamento de uma tendência geral

A segunda regressão (Modelo II) traz as mesmas variáveis da anterior, com o acréscimo de termos interativos entre os grupos ocupacionais e os níveis de ensino. Com essas variáveis é possível distinguir o efeito diferencial do ensino superior sobre cada ocupação.

O gráfico a seguir traz a variação dos prêmios salariais médios de todos os níveis de ensino, calculados a partir dos coeficientes de regressão do primeiro modelo.

Controlando por todas as variáveis inclusas no modelo de regressão, a renda de um indivíduo com ensino superior, em 1995, era em média 92,9\% maior do que a dos que possuíam ensino médio; por sua vez, a renda desses últimos era $36,9 \%$ superior à daqueles com apenas ensino fundamental; e, por fim, a renda das pessoas com ensino fundamental era cerca de $31 \%$ maior quea daqueles sem nenhum nível de escolaridade completo. Assim, por exemplo, mantidas constantes todas as variáveis incluídas no exercício (isonomia quanto a sexo, idade, região etc.), se dentro de um mesmo grupo ocupacional um indivíduo sem níveis de estudo completos ganhasse 1 real, com ensino fundamental ele ganharia 1,31 real, com ensino médio 1,79 real e, com ensino superior, 3,46 reais.

Atéos anos 2003 e2004, o efeito do diploma de ensino superior fazia a renda se elevar, em média, 90\% com relação ao ensino médio. Desde então, essa diferença percentual inicia uma trajetória de queda - com marcada acentuação nos últimos três anos da série. Os prêmios salariais 


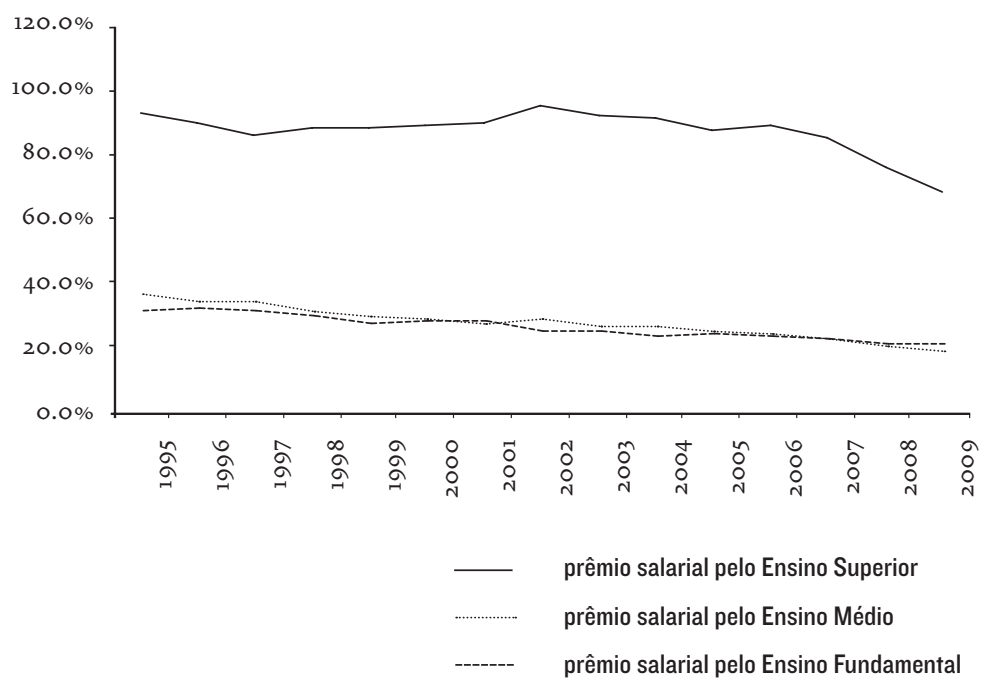

pelo ensino médio e pelo ensino fundamental também esboçam queda, embora bem mais suave, desde o início do período. Em 2009, o prêmio pela graduação era de 68,5\%; pelo ensino médio, 18,9\%; e pelo ensino fundamental, 21,2\%. De forma comparativa, é como se, para um mesmo grupo ocupacional, um indivíduo sem níveis de escolaridade completos ganhasse 1 real, teria sua renda elevada para 1,21 real com o ensino fundamental; para 1,44 real com ensino médio; e para 2,43 reais com o superior. Até aqui esses dados revelam a queda generalizada dos diferencias de renda do trabalho, na última década, produto da elevação mais que proporcional da renda dos estratos inferiores, explicável pela política de salário mínimo e pelo aquecimento do mercado de ocupações de menor qualificação. Não se deve perder de vista, ainda, o fato de que a posse do diploma de nível superior no Brasil paga um enorme prêmio salarial.Supor que esse prêmio deveria aumentar, para que se justificasse a expansão do ensino superior no Brasil ou o esforço dos indivíduos que buscam maior escolaridade é o mesmo que dizer que o efeito da expansão do ensino deveria ser o aumento das desigualdades de renda no Brasil.

Observando, separadamente, os grupos ocupacionais, as tendências são variadas. Apenas no ano de 2007 todas as ocupações registram queda no prêmio salarial dos graduados, mas, mesmo assim, não de forma homogênea. A série de gráficos abaixo (Gráficos

[9] Trata-se de dois homens, negros, com 35 anos de idade, assalariados formais, residentes na região Sudeste, trabalhadores do setor da indústria tradicional, com 40 horas de jornada de trabalho semanal. 8Aa 8C) traz o Grande Grupo Ocupacional dos trabalhadores da indústria pesada (GG8) como ilustração da tendência descrita acima. Em primeiro lugar, foram estimados, através do segundo modelo de regressão, o salário médio de dois indivíduos neste G G, um com ensino médio e outro com ensino superior ${ }^{9}$ (Gráfico 8A). Como todas 


\section{GRÁFICO 8A}

Salário médio estimado (Modelo II) para indivíduos com ensino médio e ensino superior no grupo 8 (1995-2009)

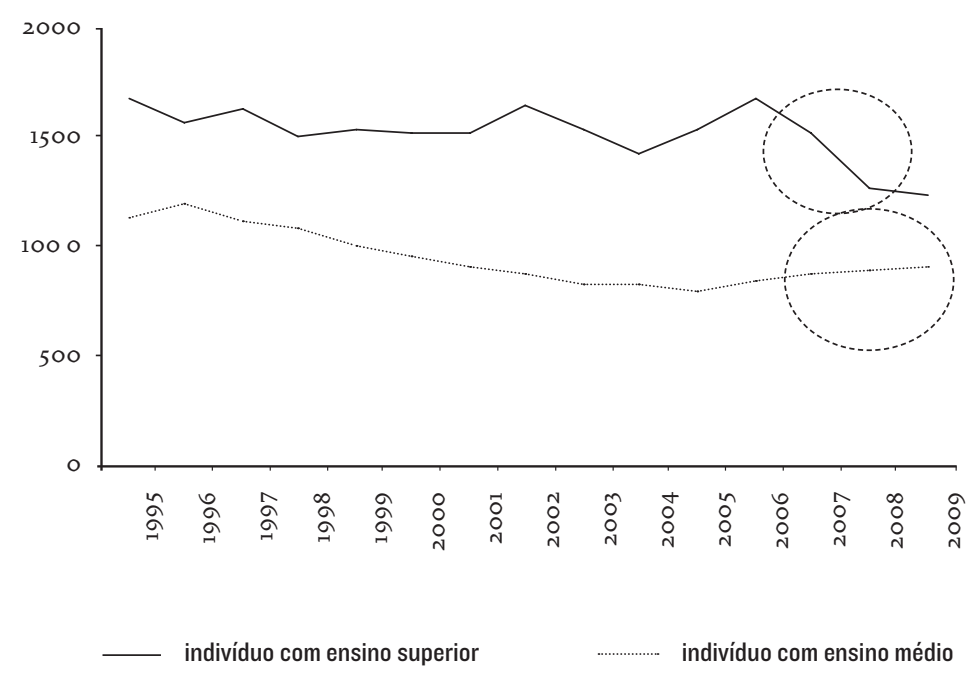

\section{GRÁFICO 8B}

Valor estimado (Modelo II) para o prêmio Salarial pela graduação no grupo 8 (1995-2009)

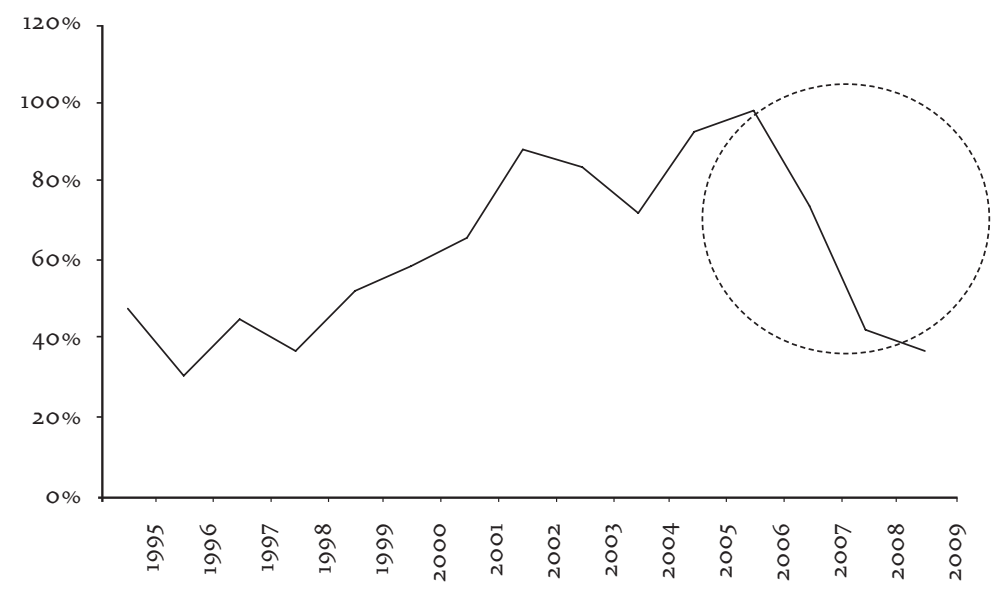

as demais características foram mantidas constantes, toda diferença entre as duas curvas que mostram a evolução dos salários estimados se deve à credencial de ensino superior. Nota-se que a renda do indivíduo com ensino médio assinala uma trajetória uniformemente decrescente até 2005 , quando então esboça uma leve recuperação. A renda dos graduados se mantém relativamente estável até 2006 , quando sofre perda expressiva. Como resultado, o prêmio salarial, que até então vinha crescendo, apresenta uma queda súbita e acentuada nesses últimos anos (Gráfico $8 \mathrm{~B}$ ). O terceiro gráfico (8C) mostra que esses anos de queda do prêmio salarial coincidem com 
GRÁFICO 8C

Número absoluto de graduados no Grupo 8 (1995-2009)

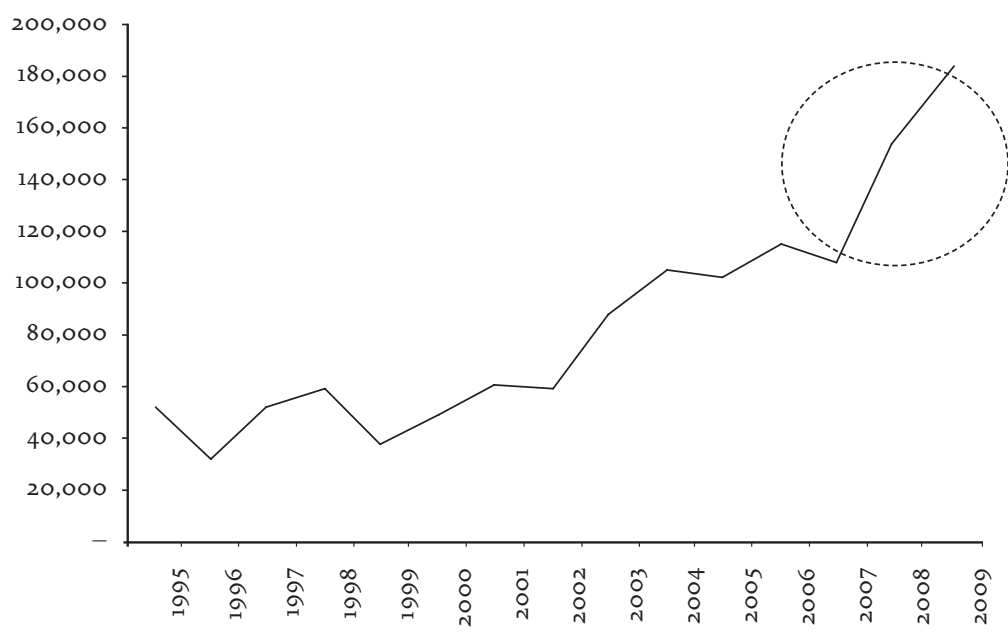

o crescimento do número de graduados nesse grupo ocupacional: em 2007, havia cerca de 115 mil indivíduos portadores de diploma superior no grupo 8 . Esse número se eleva para mais de $180 \mathrm{mil} \mathrm{em}$ 2009 - é o maior crescimento, em todo o período considerado.

Tendências semelhantes podem ser encontradas para os grupos 5 , 6 e 7 (todos com baixa densidade de graduados): há um decréscimo da renda do ensino médio até cerca de 2004 , o que faz com que o prêmio salarial se eleve momentaneamente. Cresce então o número de indivíduos com ensino superior: em 2005 , havia cerca de 66 mil graduados no grupo 5, 21 mil no grupo 6 e 131 mil no grupo 7. Em 2009 esses números vão para 154 mil, 54 mil e 246 mil, respectivamente. Ou seja, a presença de pessoal com ensino superior dobrou ou mais que dobrou em apenas quatro anos em todas essas ocupações.

No grupo 9 a tendência é um pouco diferente. Tanto o salário daqueles com ensino médio como daqueles com ensino superior sofreram baixas até 2005 . Por isso, o prêmio salarial ficou estável, em torno dos $80 \%$. No entanto, em 2007 , e também de forma fortemente correlacionada ao crescimento dos graduados nesse grupo, assiste-se a uma drástica redução dessa diferença de renda, fazendo com que a vantagem salarial média dos graduados caia pela metade, para $40 \%$.

Nos grupos 1 e 4, grupos com maior densidade de graduados, o prêmio salarial se mantém estável até 2007 , quando ocorre uma queda, porém de menor intensidade, se comparada à dos grupos citados anteriormente. No grupo 1, o prêmio era cerca de $80 \%$, caindo para $65 \%$, enquanto no grupo 4 flutuava ao redor dos $70 \%$, caindo para $50 \%$. Há que se considerar que o crescimento do número absoluto de graduados nos grupos r e 4 é intenso durante todo o período (1995-2009), 


\section{GRÁFICO 9A}

Percentual de estudantes de graduação por idade dentre os ocupados no Grupo 2 (1995 e 2009)

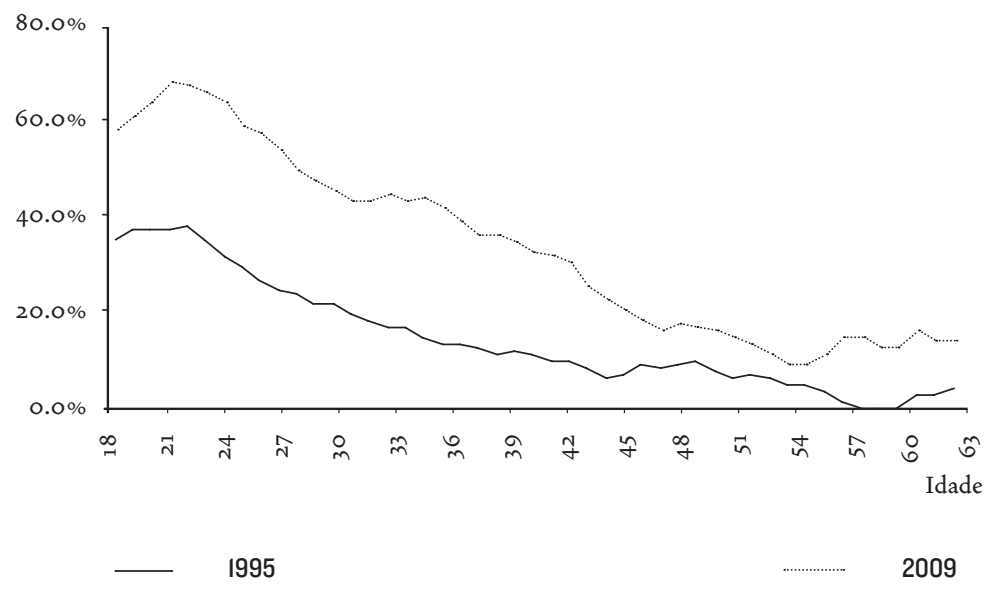

\section{GRÁFICO 9B}

Percentual de estudantes de graduação por idade dentre os ocupados no Grupo 4 (1995 e 2009)

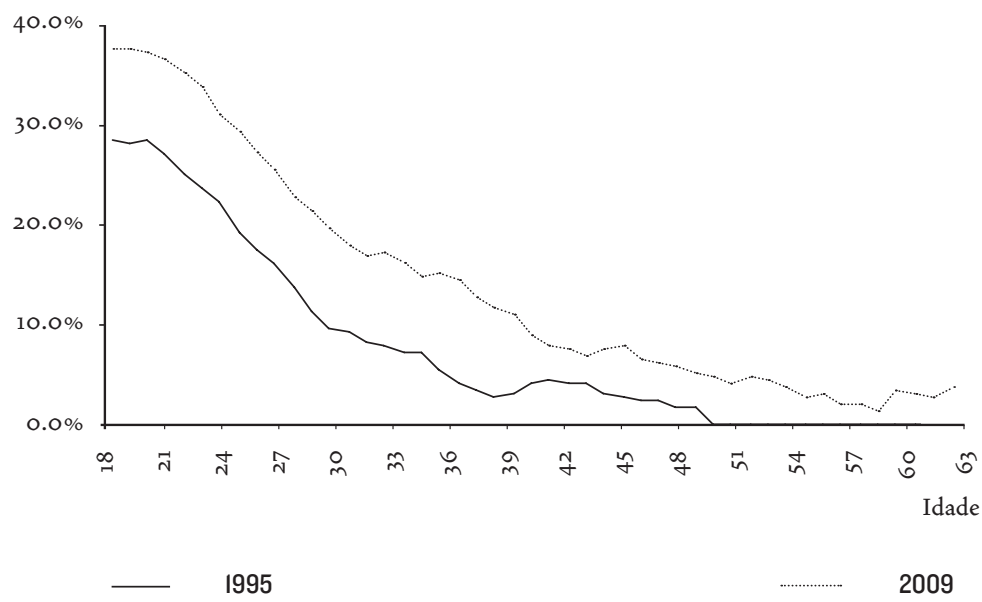

mas segue um padrão de evolução linear, sem grandes saltos (diferentemente do que ocorre nos grupos 5, 6, 7, 8 e 9). Nos grupos $2 \mathrm{e}$ 3, o prêmio salarial se reduz continuamente, durante todo o período, de maneira lenta e gradual. E nesses grupos também a quantidade de graduados evolui de forma linear, sem saltos.

De modo geral, portanto, a crescente presença de graduados no mercado de trabalho coincide com a redução dos diferencias de renda entre estes e o grupo dos indivíduos com apenas o ensino médio. Coincide, mas não necessariamente a explica, no sentido usualmente associado à tese da inflação de credenciais, que supõe que a oferta "exagerada" de pessoas com escolaridade superior obrigaria esses indivíduos a se empregarem em ocupações de baixa qualificação. 

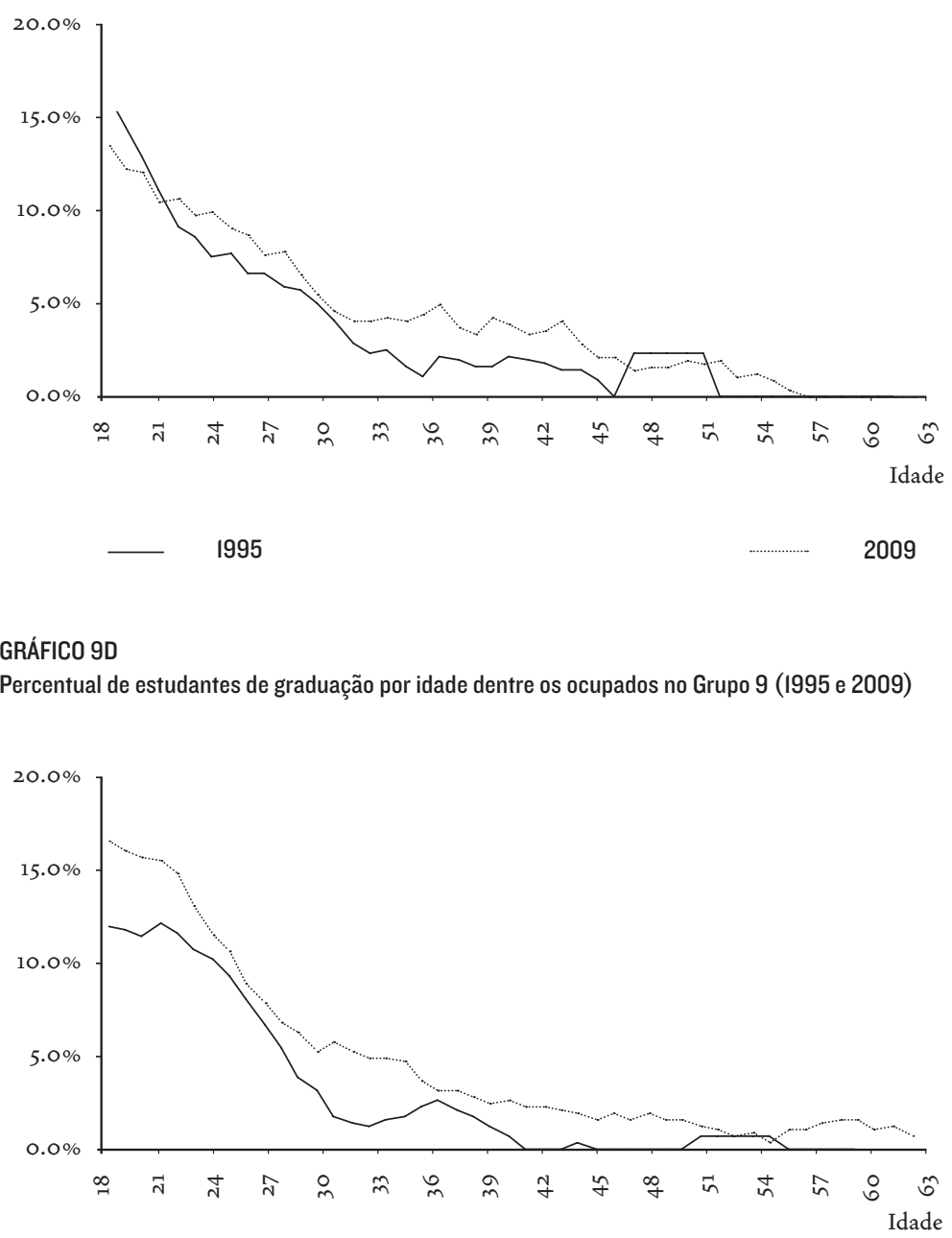

A série de Gráficos 9 compara a distribuição do número de estudantes de graduação por idade (indivíduos de 18 a 64 anos) e por ocupação, em 1995 e 2009 . Ao tomar os estudantes de graduação, e não os graduados, pretende-se enfatizar a hipótese de que a relação entre ocupação e nível escolar, no Brasil,é, especialmente para os contingentes afluentes, "invertida"; ou seja, é a condição de ocupados e a experiência ocupacional dos indivíduos que os leva a buscar o ensino superior. A seleção dos grupos ocupacionais apresentados pretende ilustrar dois segmentos opostos do mercado de trabalho, com, respectivamente, dois exemplos cada.

Os grupos 2 (Gráfico 9A) e 4 (Gráfico 9B) colecionam ocupações para as quais a posse do diploma de ensino superior pode ser considerada estratégica. Em ambos, observa-se um aumento generalizado, 
em todos os grupos etários, do número de estudantes, o que, de certa forma,éesperado, considerando que são indivíduos com maiores rendimentos (capazes de suportar os custos de estudar), ocupados em áreas em que o diploma de nível superior pode representar impulso significativo em suas carreiras.

Os grupos 7 (Gráfico 9C) e 9 (Gráfico 9D) representam ocupações para as quais não se supõe que o diploma de nível superior seja um requisito objetivo. Também aqui se observa crescimento entre os dois períodos; contudo, deve-se notar queé principalmente nas idades mais avançadas que a curva de 2009 se descola mais da curva de 1995. Para esses dois grupos ocupacionais é entre os indivíduos com mais de 30 anos que a proporção de estudantes se amplia mais acentuadamente. Em todas as ocupações ainda são os mais jovens a maioria dos estudantes de graduação. Mas a novidade, com relação a 1995, é que há um crescimento específico dos mais velhos nos grupos ocupacionais de menorstatus e rendimento.É isso que ajuda a explicar o crescimento acelerado do número de graduados nesses grupos. Lembrando (Gráfi$\mathrm{Co} 4$ ) que esses grupos perderam terreno em termos absolutos para os grupos de 1 a 5, presume-se, neste caso, que a busca pelo incremento educacional esteja associada: a) ao imperativo de sobreviver em carreiras que encolhem (acirrando a concorrência entre os que permanecem) e ao fato de que, como se viu, há um prêmio salarial substantivo (ainda que declinante) para os graduados nessas ocupações, evidência de que sua credencial escolar mais elevada é valorizada no mercado; ou b) a estratégias de mobilidade sócio-ocupacional ascendente, vale dizer, a tentativas de migrar para outras profissões mais atraentes.

\section{Conclusões}

A rápida expansão do ensino superior no Brasil é explicada tanto pelas mudanças institucionais e regulatórias quanto por uma série complexa de mudanças (não necessariamente convergentes) no mercado de trabalho, nestas últimas duas décadas. Assim como o desemprego muito elevado dos anos 1990 - que atingiu especialmente trabalhadores dos setores industriais - deve ter empurrado muitos indivíduos de "volta para a escola", como forma de aumentar sua "empregabilidade" (essa era a palavra da moda, então); o aquecimento do mercado de trabalho e o aumento da renda dos mais pobres lhes infundiram otimismo e renda para suportar a árdua convivência de jornadas extensas de trabalho com o estudo noturno.

Os dados mostram que o número de graduados (e de estudantes de graduação) cresce em todos os grupos de ocupações, refletindo não necessariamente as demandas do mercado de trabalho, mas estratégias muito variadas (e que nossos dados não nos permitem senão es- 
[10] Sem excluir, naturalmente, que esses fatores podem também ter colaborado para essa redução.
Recebido para publicação em 9 de outubro de 2011.

\section{NOVOS ESTUDOS}

pecular a respeito) de inserção e progressão profissionais. Em todos os casos, porém, possuir um diploma de nível superior está associado a significativos prêmios salariais. Os prêmios salariais declinantes na última década devem-se muito mais ao movimento generalizado de redução dos diferenciais salariais - fruto do crescimento dos salários mais baixos - do que a um excesso de oferta de trabalho qualificado ou à baixa qualidade do ensino superior ${ }^{10}$. Não foi apenas entre diplomados e não diplomados que as diferenças salariais encolheram, em termos relativos; o mesmo se observa entre homens e mulheres, brancos e negros, jovens e adultos, regiões mais pobres e mais ricas.

Não é exagero dizer que, quanto à premente necessidade de o Brasil elevar seus níveis de escolaridade, os cidadãos comuns, especialmente aqueles oriundos de famílias mais pobres, têm feito sua parte. Que a educação seja de baixa qualidade e que o mercado de trabalho não crie em número suficiente as oportunidades para que o investimento feito por eles em educação se realize plenamente são assuntos de outra alçada; dizem respeito à qualidade do desenvolvimento econômico. Dispordeuma força de trabalho mais qualificada confere ao país maior escopo para "escolher" seus rumos de desenvolvimento e, a esse respeito, mais educação é sempre melhor do que menos educação. A tarefa de evitar que lamentemos, no futuro, ter muita gente qualificada e poucas ocupações condizentes não serácumpridaexclusivamente pela política educacional; a situação atual de vários países europeus parece sugerir isso de forma sombria.

No Brasil, o padrão peculiar encarnado na figura do trabalhador-estudante não é exatamente novo, já que desde sempre os indivíduos mais pobres têm sido atraídos para o mercado de trabalho em idade muito precoce, o que lhes reserva como melhor cenário possível a combinação entre trabalho e estudo. A novidade éque este padrão tem viabilizado a expansão do ensino superior, na escala a que assistimos, dada a prevalência do ensino pago e a cobertura ainda muito insuficiente das políticas de subsídio e inclusão.Ainda que esse seja um padrão transitório, que ao longo das próximas gerações dê lugar ao canônico modelo das transições escola-trabalho (mas essa é apenas uma possibilidade), é decisivo que o Estado brasileiro (sob as diversas formas em que ele se materializa e atua) seja capaz de garantir, o quanto antes, que o "produto" que estes indivíduos estão adquirindo no mercado tenha, pelo menos, as características que suas embalagens prometem. Além de fazer valer o direito do consumidor, estaríamos ampliando o leque de possibilidades das políticas de desenvolvimento.

Alvaro A. COMin é professor do King's College London - Brazil Institute; professor licenciado do departamento de Sociologia da FFLCH-USP e pesquisador associado ao CEM/Cebrap. ROGÉRIO JERÔNIMO BARBOSAé pesquisador do CEM/Cebrap. 